\title{
UMA POSSÍVEL LEITURA DE MEMÓRIAS PÓSTUMAS DE BRÁS CUBAS
}

Rodrigo Vasconcelos Machado*

RESUMO:

Este ensaio investiga a presença de elementos da estética do grotesco na maquinaria de Memórias Póstumas de Brás Cubas. Para tanto, se vale das contribuições não só da fortuna crítica machadiana como também das reflexões sobre o grotesco, principalmente as de Mikhail Bakhtin, Wolfgang Kaiser, Robert Klein e Ramón del Valle Inclān.

PALAVRAS-CHAVE: Machado, Memórias Póstumas, grotesco, Sterne.

Estudar um objeto que possui uma vasta exegese requer por parte de quem o empreenda um conhecimento profundo da obra e da fortuna crítica do autor escolhido. Além de estar ciente dos riscos que aporta, o estudioso necessita de coragem para fazer sua análise. No caso de MACHADO DE ASSIS, os problemas se agravam pela própria imensidão da obra, que desde o início de sua carreira intelectual foi reconhecido pelos seus pares, tendo tido em vida o aplauso do público e de quase da totalidade da crítica; contudo investigar um autor fundador da Literatura Brasileira traz inúmeros benefícios. Entre eles se destaca o convívio com uma escrita vigorosa e fecunda, que mudará em muito a compreensão de mundo, ou seja, a possibilidade de estabelecer novas relações intertextuais em função da abundância de referências literárias e, principalmente, contribuir com um estudo analítico que acrescentará à fortuna crítica uma nova interpretação.

A grandeza de MACHADO DE ASSIS decorre não apenas da realização estética de seus textos, como também da permanência dos mesmos. 0 escritor descortinou um novo panorama na Literatura Brasileira. Temos em sua produção ficcional da maturidade intelectual a discussão de questões que foram retomadas por vários escritores |* Mestre em Letras: Estudos Literários (Área de concentração: Literatura Brasileira), 2000. 


\section{EM TESE}

Belo Horizonte, v. 5, p. I-305, dez. 2002

posteriores a ele. Para compreendê-las melhor, propomos voltar o nosso olhar para um texto que reunisse em si técnicas que seriam aperfeiçoadas nas obras subseqüentes e a escolha recaiu em um romance que apontou novas possibilidades e é considerado divisor de sua obra ${ }^{1}$ : Memórias póstumas de Brás Cubas $^{2}$. A data da primeira edição em livro é de $1881^{3}$.

A modernidade das grandes narrativas, revestidas na superfície com matizes arcaicos, suscita a pergunta de como ocorreu a transformação do romance da sociedade e de tipos humanos para o do escritor maduro de MPBC, Dom Casmurro, entre outras obras. No romance temos vários elementos que aprimoraram o legado da tradição e foram além do que se fazia na época. Pode se dizer que esta nova fase na produção ficcional foi uma verdadeira renovatio. Para compreender melhor essas transformações, este estudo buscará compreender o grotesco no romance como elemento decifrador do humor, isto é, a leitura de MPBC será feita levando-se em conta as relações intertextuais com obras que apresentam o "sentimento de contrastes"4. A aplicação do grotesco como elemento revelador aporta problemas antitéticos, pois o trabalho desenvolvido por MACHADO DE ASSIS se aproxima muito do neoclássico no sentido tradicional, como o esmero nas questões sintáticas e o cuidado com o léxico, e que, associado à idéia de grotesco, torna-se um contra-senso. A procura de um objeto artístico de fatura impecável caminha, todavia, de mãos dadas com o anticlássico. Esta tensão dialética entre dois conceitos demonstra que o antigo traz as condições de ruptura. Para ilustrar melhor, pensemos no caso de Fillipo BRUNELLESCHI, que projetou e construiu a Cúpula da igreja de Santa Maria del Fiore, em Florença. Segundo Giulio Carlo ARGAN, o arquiteto florentino estudou os antigos modelos romanos para solucionar o problema de construir uma cúpula sem necessidade de cimbres e sua resposta foi a renovação do método técnico, mas, ao transpor o clássico para o presente, o afastou da sua historicidade, contradizendo-o:

Por isso, o método construtivo está relacionado com a renovação do método técnico; a partir desse momento, todo ato artístico vale enquanto interrompe a tradição, e não enquanto a continua; daí em diante, todo ato implica a consciência do ato, e todo momento "prático" um momento "teórico". ${ }^{5}$

0 classicismo é uma linguagem que foi enriquecida por "neologismos", engendrando algo diferente. Daí que para ARGAN, o anticlassicismo consiste na 
transformação do antigo em moderno ${ }^{6}$, conjugado com uma qualidade humana reencontrada nas "ruínas": a indústria e a sutileza. Assim o modelo do passado se apresenta preenchido com conteúdos modernos; tal esquema se visualiza como uma "teoria que é história"7, pois se aperfeiçoa ao largo do tempo, e corresponde a uma práxis que se modifica e adapta às necessidades e circunstâncias práticas do presente. Esta práxis não pode ser considerada uma mera cópia de um modelo a priori, ao contrário se realiza a partir de um fundamento de experiência histórica, uma finalidade própria: é a determinação de um processo, isto é, de um projeto, que ao consolidar a forma adquire a plenitude expressiva que não tinha no seu início.

Podemos aproveitar as ponderações de ARGAN para estabelecer uma analogia com o novo modo empregado por MACHADO DE ASSIS, a fim de atingir a maturidade em sua ficção. A diferença com as obras iniciais e com outros autores do mesmo período configura-se no uso de procedimentos narrativos provenientes da tradição do 0cidente. Considerando MPBC na sua integridade de objeto, observamos a presença, por detrás de sua superfície, de várias "camadas" sobrepostas, que são influências, como declara o narrador no seu prefácio de abertura ${ }^{8}$. Uma das "camadas" seria, por exemplo, a fragmentação dos capítulos e a inserção de outros símbolos gráficos no corpo da narrativa. Estas "técnicas" existiam na literatura de Laurence STERNE e MACHADO DE ASSIS se encontrava na necessidade de reinventá-las. Buscou nos ingleses e outros modelos literários as condições para ultrapassar o que se fazia na sua época. A redescoberta da técnica anterior a ele possibilitou que a adequasse ao seu tema considerando a sua posição na sociedade do II império.

Da mesma forma que BRUNELLESCHI, foi além do que havia no exterior para se deter com maior cuidado na profundidade. A arte de propor uma crítica, que registrava em seus subentendidos os contrastes da natureza humana, fez com que o público e parte dos estudiosos de MPBC cometessem erros de apreciação. Daí, a presença de juízos que se baseavam no que a obra representava, isto é, consideravam o livro "risonho" e com laivos de pessimismo. Talvez as elites do século XIX não quisessem vê-10 como uma crítica às iniqüidades sociais. MACHADO DE ASSIS, com a sua ascensão social na sociedade escravista, pôde deslocar o seu olhar para um novo lugar, a fim de esmiuçar os mecanismos de dominação pela ironia fina e pelo humor, isto é, exige que o seu leitor leve em conta todas as condições de produção que estão 


\section{EM TESE}

Belo Horizonte, v. 5, p. I-305, dez. 2002

envolvidas no processo criativo:"(...) diante de uma obra de arte é necessário interrogar-se sobre o pensamento do artista quanto ao estar aqui dela, ao seu "estar no mundo", tendo um passado agindo no presente, considerando um futuro possível." 9

A demanda por uma leitura intertextual de MPBC através da questão do grotesco se faz pela necessidade de interrogar-se sobre o pensamento deste artista quanto ao "estar aqui" de seu livro e a sua posterior permanência no cânone da Literatura Brasileira. As variações de MPBC permitem analisar nas entrelinhas, nas suas dobras e desdobramentos, como o influxo de outros textos contribuíram para o surgimento de um romance que condensava em sua tessitura narrativa técnicas que seriam consolidadas pela ficção do século XX. As formas oriundas de outras fontes também estavam carregadas com os seus valores, que foram reelaborados com o que 0 romancista pôde captar.

Ao transpor o grotesco para outro contexto histórico-social, o escritor empreendeu uma aventura literária cheia de riscos, mas o resultado final foi criar uma narrativa que dialoga com uma vasta tradição e que a reflete de modo crítico. Muito se tem dito sobre a "alienação" da obra; entretanto podemos sugerir que se retomam na tessitura da narrativa procedimentos literários do 0cidente, que parecem, num primeiro momento, passivos e inócuos. 0 fim de todas as tentativas humanas que dão no abismo do vazio, isto é, o sentimento de Brás Cubas de que nada na vida alcança uma meta ou um término engendra na forma narrada a volubilidade. 0 capricho do narrador, ao descartar tudo com que encontra no seu caminho, tem consideráveis conseqüências estruturais, pois leva a enfatizar a natureza episódica e a irrelevância de todos os acontecimentos. Com isso, gera no texto a fragmentação digressiva, que se funda numa espécie de renúncia a toda organização linear, a toda concentração e integração. MACHADO DE ASSIS preferiu expressar-se numa forma "ex-cêntrica" de composição, que registrava a violação do quadro de referência da tradição.

MPBC aporta na sua tessitura elementos do grotesco, que configuram uma visão de mundo onde predominam os contrastes das situações. Rastrear estes componentes possibilitou orientar a leitura, contemplando os seus altos e baixos e constatar que a matéria narrada os absorveu e, de certo modo, os conservou.

Muitos questionariam como se pode aproximar um texto de fins do século XIX com uma estética que teve o seu apogeu na Idade Media e no Renascimento. Nesse 
momento voltamos o nosso olhar para o que o texto nos permite. E nos deparamos com o influxo de procedimentos literários oriundos do "sentimento de contrastes". Os paradoxos que se abrandam requeriam um novo tipo de aproximação que buscasse indagar sobre o papel do humorismo como um elemento que contrabalançava o pessimismo verificado na matéria narrada.

As diferenças de MPBC com outros textos escritos à luz do grotesco, conforme conceituado por BAKHTIN, são muitas e exigem que se guarde a especificidade de cada uma no momento em que vão ser analisadas. Contudo os "destroços" do realismo grotesco estavam latentes na tradição e amadureceram no texto. A elegância do romancista ao retratar situações que variavam do riso à lágrima evitou que a estrutura da matéria narrada perdesse tensão. Assim, a separação entre o significado e o significante tem como objetivo a exageração do primeiro, correspondendo ao registro da "desfaçatez de classe", para em seguida se desdobrar na crítica da artificialidade das relações humanas. Comprovamos, então, que o texto, ao se valer do grotesco, harmoniza o humorismo e o pessimismo, para realizar uma crítica atemporal à decadência dos valores.

0 "arcaizante" presente na obra determinou a sua continuidade dentro da tradição, na medida em que o ficcionista resgatou procedimentos técnicos que o possibilitaram ir muito a frente do que se fazia no seu tempo. Por trás de uma superfície literária estilisticamente "ultrapassada" pelo realismo do Naturalismo, existia para o leitor um novo pacto de leitura, onde a ingenuidade foi subrepticiamente substituída por uma complexidade recorrível em todos os sentidos. Brás Cubas, por um lado, controla a decifração do texto, por outro, o segundo narrador torna possíveis modos de interpretação incontroláveis, como se pode constatar. No interior da composição se dá uma nova maneira de retratar a realidade brasileira de forma fragmentada e digressiva. São resquícios do real que captam e fixam o retrato dos abusos das elites e a posição do ser humano diante do vazio da existência. Temos, então, a fragmentação da identidade do narrador-protagonista que se estende para a ruptura da linearidade da narrativa. Destarte MPBC configura-se como um texto antecipador de algumas das inovações da modernidade, entre as quais figuram a noção da existência de dois tempos e o jogo dialético entre o antigo e o moderno. 


\section{EM TESE}

Belo Horizonte, v. 5, p. I-305, dez. 2002

Em MPBC comprovamos a existência de um universo ficcional que retrata de forma condensada problemas que ainda estão vigentes. Pensamos que a volubilidade da natureza humana se apresenta para nós como um dos principais elementos da maquinaria do romance, à luz de uma escrita que desvenda, pelas deformidades realizadas com os objetos do real, a artificialidade das relações humanas, que são baseadas na total incomunicabilidade. As verdades privativas infelizmente estão no comando das situações, isto é, os homens se deixam levar por suas paixões e acabam terminando no nada. Da mesma maneira que Brás Cubas, se mostram como esperpentos vivos, conforme a noção desenvolvida por INCLÁN ${ }^{10}$. Cumpre ressaltar que existe a saída do humorismo, que como uma válvula de escape, possibilita que tudo seja relativizado e o medo diante do salto para o vazio seja enfraquecido e substituído pelo riso.

NOTAS:

1. A divisão da obra machadiana em duas fases é apenas uma convenção que empregamos para facilitar este estudo, pois se deve considerar que os romances iniciais foram publicados num curto espaço de tempo (de 1872, Ressurreição, a 1878, Iaiáa Garcia).

2. Doravante quando referirmos a Memórias Póstumas de Brâs Cubas, usaremos a abreviatura MPBC. Utilizaremos o volume da Editora Globo, de 1997, o qual não determina o número da edição.

3. Em 1880, MPBC saiu na Revista brasileira, de março a dezembro. Cf. ASSIS, 1994, p. 25 .

4. BOSI, 1997, p. 20.

5. Cf. ARGAN, 1999, p. 131.

6. Idem, ibidem, p. 130-131.

7. Idem, ibidem, p. 424.

8. Prólogo ao leitor inserido a partir da $3^{a}$ edição de 1886.

9. ARGAN, 1999, p. 24.

10. Utilizo o seguinte conceito:"Estoy iniciando un género nuevo, al que 11 amo género estrafalario. Ustedes saben que en las tragedias antiguas, los personajes marchaban al destino trágico, valiéndose del gesto trágico. Yo en mi nuevo género también conduzco a los personajes al destino trágico, pero me valgo para ello del gesto ridículo. En la vida existen muchos seres que 1levan la tragedia dentro de sí y que son incapaces de una actitud levantada, resultando, por el contrario, grotescos en todos sus actos". Cf. INCLÁN, 1988, p. 22. 
RÉSUMÉ:

Cet étude prétend analyser la présence du grotesque dans la composition du roman Memórias Póstumas de Brás Cubas, de l'écrivain Machado de Assis. Nous utilisons les réflexions de la critique brésilienne, aussi bien que des oeuvres sur le grotesque, écrites par Mikhail Bakhtine, Wolfgang Kayser, Robert Klein et Ramón del Valle Inclán. De la même façon, nous prétendons étudier l'impact de l'oeuvre La vie et les opinions de Tristram Shandy, de Laurence Sterne, sur l'écrivain.

MOTS-CLÉS: grotesco, Sterne, Machado de Assis, esperpento.

REFERÊNCIAS BIBLIOGRÁFICAS:

ARGAN, Giulio Carlo. Clássico anticlássico: o Renascimento de Brunelleschi a Bruegel. São Paulo: Companhia das Letras, 1999.

ASSIS, Machado de. Obra completa. Vols. 1, 2 e 3. COUTINHO, Afrânio (Org.). Rio de Janeiro: Nova Aguilar, 1994.

BAKHTIN, Mikhail. Marxismo e filosofia da linguagem. São Paulo: Hucitec, 1992.

- A cultura popular na Idade Média e no Renascimento: o contexto de François Rabelais. São Paulo: Hucitec/Eub, 1993a.

CANDID0, Antonio. Silvio Romero: teoria, crítica e história literária. Rio de Janeiro/ São Paulo: INL/ Edusp, 1978.

- A educação pela noite \& outros ensaios. São

Paulo: Ática, 1989. - Formação da literatura brasileira. (vols. 1 e 2). Belo Horizonte: Itatiaia, 1993.

. Esquema de Machado de Assis. In: Vários escritos. São Paulo: Duas cidades, 1995.

- Dialética da malandragem. In: ALMEIdA, Manuel Antônio. Memórias de um sargento de mílicias. Ed. crítica de Cecilia Lara. Rio de Janeiro: LTC, 1978.

GAMA, Lopes. O carapuceiro: crônicas de costumes. São Paulo: Companhia das Letras, 1996.

HUGO, Victor. Do grotesco e do sublime. Tradução do prefácio de Cromwell. BERRETInI, Célia (Org.). São Paulo: Perspectiva, 1988. 


\section{EM TESE}

Belo Horizonte, v. 5, p. I-305, dez. 2002

INCLÁN, Ramón de Valle. Luces de Bohemia. Esperpento. VICENTE, Alonso Z. (Org.). Madrid: Espasa Calpe, 1998.

KAISER, Wolfgang. O grotesco. São Paulo: Perspectiva, 1986.

KLEIN, Robert. A forma e o intelígível: escritos sobre o Renascimento e a arte moderna. São Paulo: Edusp, 1988.

LIMA, Luís Costa. Dispersa demanda: ensaios sobre literatura e teoria. Rio de Janeiro: Francisco Alves, 1981.

MOOG, Vianna. Heróis da decadência. Rio de Janeiro: Civilização Brasileira, 1964.

PAES, José Paulo. Sterne ou o horror à linha reta. In: STERNE, Laurence. A vida e as opiniões do cavalheiro Tristram Shandy. Rio de Janeiro: Nova Fronteira, 1984.

SCHWARZ, Roberto. Que horas são? Ensaios. São Paulo: Companhia das Letras, 1987. $\overline{1987 .}$ - Ao vencedor as batatas. São Paulo: Duas cidades, - Um mestre na periferia do capitalismo. São Paulo: Duas cidades, 1990.

STERNE, Laurence. A vida e as opiniões do cavalheiro Tristram Shandy. Rio de Janeiro: Nova Fronteira, 1984. 